\title{
Defining Agile Culture: A Collaborative and Practitioner-Led Approach
}

\author{
Peggy Gregory \\ School of Physical Sciences \& Computing \\ University of Central Lancashire \\ Preston, UK \\ ajgregory@uclan.ac.uk
}

\author{
Katie Taylor \\ Agile Business Consortium \\ Ashford, Kent, UK \\ katie@agilebusiness.org
}

\begin{abstract}
Agile transformation requires more than the adoption of new practices, it also requires a change of behaviours, norms and mindset across the organisation. This suggests that organisations need to change their culture to become more agile. But what is Agile culture? In this paper we explore how a group took a collaborative and practitioner-led approach to developing a definition of Agile Culture and a set of tools to aid cultural assessment. We tell the story of the process, discuss the artefacts created, and analyse the approach taken using a model of interdisciplinary collaboration.
\end{abstract}

Keywords-Agile
Interdisciplinary Work $\quad$ culture; Organisational Agility;

\section{INTRODUCTION}

Agile approaches for software and IT were introduced by a group of IT consultants and thought leaders who agreed a set of values and principles in the Agile manifesto in 2001 [1]. These practitioners developed their methods from experience and experimentation in the workplace although many of the underpinning concepts were well-known [2]. Agile approaches are people-centred and they advocate an empowered and collaborative way of working that is very different from traditional IT project management approaches. As a result, teams and organisations embarking on an Agile transformation are not just making changes to their work practices but are readjusting their culture [3, 4].

We explore a practitioner-led, interdisciplinary, collaborative approach to creating innovative materials about Agile culture for practitioners. The work was undertaken by the Culture and Leadership (C\&L) workstream which was set up in 2016 by the Agile Business Consortium (ABC) as part of their initiative to develop a framework for Business Agility. The $\mathrm{ABC}$ is a not-for-profit organisation that promotes ideas and methods for business agility with the aim of spreading knowledge and understanding of agility more widely among the business community.

\section{METHOD}

Data was collected using interviews, observation, document review, and personal reflections. The first author followed the workstream activities, participated in a workshop and conducted three interviews with team members. The second author was the C\&L team lead, participated in all meetings and workshops and was involved in developing documents. Data was analysed to identify key events, ways in which the team worked, and objectives. This highlighted the importance of interdisciplinary team work leading to the use of Bronstein's Interdisciplinary Collaboration Model [5] as a theoretical lens

\section{DeVeloping A VIEW of AgIle Culture}

The C\&L team lead brought together a core group of interested individuals, deliberately looking for members with a range of perspectives. This included experience of Lean/Six Sigma, psychology, systems thinking, project and programme management, and organisational development in different business sectors.

Work started on leadership and moved to culture in late 2016 with the first working draft of the Agile culture matrix (Fig 1) produced in June 2017. The core team met bi-weekly on Skype and bi-monthly face-to-face. Much, but not all, of the work was unpaid. Ideas were discussed and freely shared on the understanding that the results would be open and published as creative commons. A wider group of about 70 practitioners were invited to attend workshops to evaluate, discuss and iterate interim versions of the model.

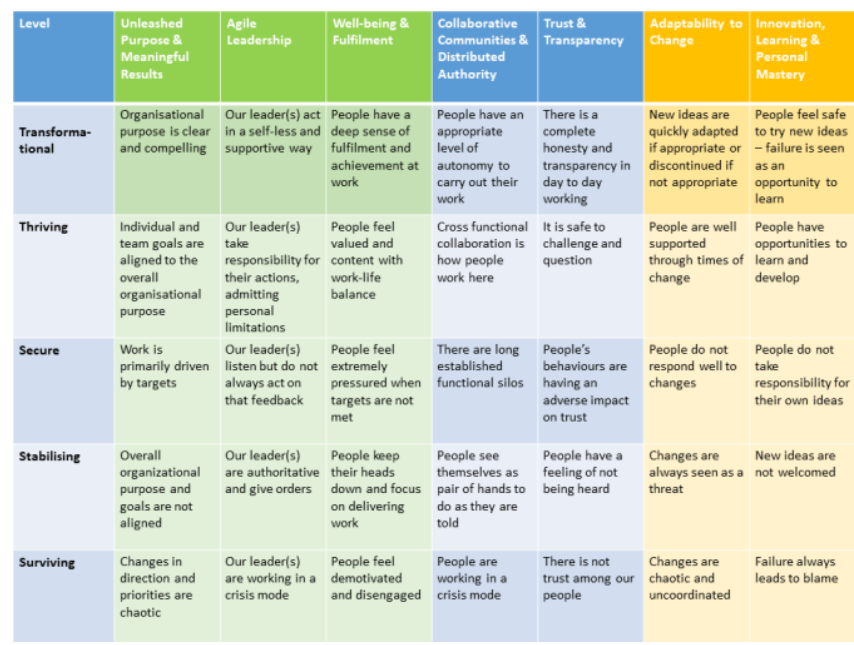

Figure 1: Agile Culture Matrix v.2

In the early stages of the culture work one team member wrote a review of literature on organisational agility and culture to identify theoretical underpinnings and trends. Literature of interest included $[6,7,8]$, but it was hard to access academic literature. This document was used as a base reference during discussions which resulted in the identification of seven elements of Agile culture [9].

Workshops were then used to gather practitioner feedback, and these identified the need to link organisational 
realities to the seven elements. This resulted in the Agile Culture Matrix (Fig 1) which used the seven elements of Agile culture as column headings. As this matured other team members saw the need to develop an assessment tool to give organisations a cultural snapshot. This resulted in the development of Pulse, a 40-question questionnaire mapped to the Agile Culture Matrix. In addition, a Coaching Toolkit was developed to support change and development of workplace culture. This 3-part toolkit (Pulse, Matrix, Coaching Toolkit) went through several iterations after piloting in three organisations.

Culture is about behaviours, attitudes, values, and beliefs. Some aspects are difficult to measure [10]. In this work, a pragmatic set of tools was developed to help practitioners understand the situation in their organisation and initiate changes towards a more Agile way of working. The team were clear that the resulting Agile Culture Matrix is not a maturity model as it may not be appropriate or feasible for all organisations to aspire to a transformational-type culture

\section{ANALYSIS}

We explore the C\&L process using the five elements of Bronstein's Interdisciplinary Collaboration Model [5].

- Interdependence refers to the reliance on interactions between team members to accomplish tasks. The free exchange of ideas was essential to the development of the elements in the Agile Culture DNA model. Regular meetings were essential for idea exchange and the development of a cohesive team. Nevertheless, some opportunities for greater interdisciplinarity were missed, for example more regular input from academics or smaller organisations such as start-ups.

- Newly Created Professional Activities refer to collaborative activities that achieve more than those undertaken individually. Working practices such as regular discussion meetings and cross-disciplinary workshops were particularly effective mechanisms. To attract attendees these had to provide immediate benefits for participants as well as meeting C\&L's long-term aims.

- Flexibility refers to role blurring. This happened through participants taking on roles that differed from the ones they used in their normal work environment. There was also flexibility in the iterative and incremental approach the team took to developing and evaluating artefacts.

- Collective ownership of goals refers to shared responsibility for goals. This was established early in the process; the goal was to develop a model of Agile Culture that was useable and useful for practitioners. The detail of how this goal would be achieved developed over time through discussion in the core team and the wider group.

- Reflection on the process refers to collaborators considering their own work process. The team ran some retrospectives, but there was some reluctance to do this due to time constraints and the team's motivation to work on new ideas.
Our analysis found some areas of difficulty even though the team was resilient, productive and innovative. They reported going through the stages of forming, storming, norming, and performing [11] during which some members left. This was perhaps inevitable as membership was voluntary. There were also some tensions between the team and the $\mathrm{ABC}$, with differences in understanding and knowledge. Opportunities for more collaboration with academics were available but not identified and followed up at the time. There were issues about practitioners from different disciplines using different language. The reluctance to engage in reflection was interesting for an agile team.

\section{CONCLUSIONS}

The contributions of this paper are an overview of the development process used by a practitioner-led collaborative team to develop a definition of Agile culture, a brief description of the artefacts produced, and an analysis of the team process using the Interdisciplinary Collaboration Model [5]. Future work will develop a 4-tier model of collaboration and evaluate the utility of the toolkit for organisations.

\section{ACKNOWLEDGMENT}

We would like to thank interview participants from the Agile Business Consortium's Agile Culture and Leadership Team.

\section{REFERENCES}

[1] K. Beck, et al. "Manifesto for Agile Software Development" 2001. www.agilemanifesto.org

[2] N. Abbas, A. M. Gravell, and G. B. Wills, "Historical Roots of Agile Methods: Where Did 'Agile thinking' Come From?" in International Conference on Agile Processes and Extreme Programming in Software Engineering. 2008, pp. 94-103, Springer, Berlin, Heidelberg

[3] D. E. Strode, S. L. Huff, and A. Tretiakov, "The Impact of Organizational Culture on Agile Method Use," in 42nd Hawaii International Conference on System Sciences. 2009, pp. 1-9. IEEE.

[4] J. Iivari and N. Iivari, "The Relationship Between Organizational Culture and the Deployment of Agile Methods." Information and Software Technology, vol. 53, issue 5, pp.509-520. 2011

[5] L. R. Bronstein, "A Model for Interdisciplinary Collaboration," Social Work, vol. 48, issue 3, pp. 297-306. 2003.

[6] R. E. Quinn, "Robert E. Quinn's Competing Values Framework," http://www.quinnassociation.com/en/robert_e_quinns_competing_val ues_framework, Accessed March 2019

[7] W. E. Schneider, The Reengineering Alternative. McGraw Hill, USA. 1994

[8] E. H. Schein, Organizational Culture and Leadership, The JosseyBass (John Wiley \& Sons), 6th Edition, London. 2016

[9] Agile Business Consortium. "Towards an Agile Culture" White Paper 2017 https://www.agilebusiness.org/resources/white-papers/towardsan-agile-culture Accessed March 2019

[10] A. Williams, P. Dobson, and M. Walters, Changing Culture: New Organizational Approaches. London: Institute of Personnel Management, 1993

[11] B. W. Tuckman, and M. A. C. Jensen, "Stages of Small-group Development Revisited," Group \& Organization Studies, vol. 2, issue 4, pp.419-427, 1977. 